\title{
Apologetic Media Research
}

\author{
LARS NyRe
}

It is supposedly not the communication researcher's job to be political, that is, to make communication into a question of conflicts of interest and societal struggle. The ideal of ethical neutrality from Max Weber prevails. Many media researchers think of this attitude as a virtue, but in my view it is apologetic.

Apologetic media research is my collective term for research projects that protect and prolong fundamental values of the media businesses without problematizing the legitimacy of these values. Such research fails to communicate its own adherence to the present order of things in a given society, and as such it promotes the means and ways of certain interest groups by 'neutrally' explaining how the media mix functions.

\section{Three Apologetic Attitudes}

I will point out apologetic tendencies in three different strands of research in the field that can broadly be called 'media studies'.

Apologies for any kind of behaviour among 'ordinary' users. This tendency is most striking in reception research and research on popular culture, where the meaning of media products in everyday social life is at the centre of attention. They care very much about what individuals and subgroups think about their own media consumption.

The user-oriented researcher often builds on his or her own identification with popular culture, be it splatter movies or blogging, and is often very generous toward the users he or she interviews and analyses. For example, interactive TV, chatting on the Internet and the expanding SMS culture are all presumed to give people greater freedom to construct their identity themselves. Here, there is a theoretical shielding of the empirical user's freedom of understanding that borders on the irresponsible.

The apologetic attitude here consists of making it appear as if people cannot be fooled or tricked, or simply be wrong. The value of understanding the user on his or her own terms is put before any other value or conflict. The researcher typically positions him or herself so that any critique of general attitudes among people can be reduced to unwarranted moralism. This is a liberal, postmodern form of 'compassionate research'. The psychological reward for taking such a position is that you will come across as a humanitarian, philanthropic researcher.

You can live comfortably with the image of being 'naive' because your motivation is so good.

Apologies for the entire journalism profession. This attitude can be found most easily in research on production practices, journalistic behaviour, program schedules and editorial value sets. It will typically be oriented to the national and regional radio, television and newspaper outlets. Such research can easily become apologetic in the sense that the researcher identifies with the rationality and purposes of editors, producers, journalists and technicians. Perhaps the researcher worked for ten years in Sveriges Radio before becoming part of the university system.

The journalism profession is seen as an ideal entity toward which empirical journalism should be helped. Journalists are in essence guided in how to become better practitioners of their profession. Researchers help them expand the effective range of present time genres (reality TV), they conduct interview-based research that analyzes the strategies of business executives and the needs of the journalist in his or her daily work. Universities or colleges that have a school of journalism are particularly vulnerable to such apologetic attitudes, and can almost be seen as institutionalized recruitment arenas for the dominant actors of the national media businesses. Very rarely is advice produced that goes contrary to what is conceived of as sensible in the journalistic profession. 
Apologies for definite business models, organizational strategies and political regulation regimes. This tendency can be found in research on institutions, media economy, political theory and the like. In practice, such research is often simply a means of administrating status quo in the media mix. Documents and protocols are filled with information about how the widespread media platforms function. Models are made describing how to manage them in the future, and generally as much as possible about their complex interrelationship with the rest of the societal structure is catalogued, so that growth can be maintained.

Administrative research is also a concept related to Paul Lazarsfeld and his research group at Columbia University in the 1940s. In this related sense it has to do with organizing the information desired by the commissioner, whether it is a media company, a PR company or a state department. Such research typically aids the further accumulation of wealth in social structures that are already dominant.

I do not mean to suggest that media researchers should stop having attitudes and tendencies that promote the current state of things in their research. This is a legitimate behaviour. I am, however, pointing out that thinking and working this way is actually a political attitude, and this should be formulated in every article and book written on the basis of this attitude. However, due to its conformity the values and ideologies are often so implicit in the structures under investigation that the researcher does not become aware of them. This is dogmatic slumber. The researcher as a meta-actor in civil society has a special duty to be aware of the bonds of loyalty that may arise in the research activity itself. Media researchers must act more honestly and wellreflected in light of this duty.

\section{Moral Opportunism}

There is a mentality among media researchers that more or less automatically discredits explicitly normative research. Such approaches are conceived of as 'moralist', 'paternalist' or 'romanticist'. Critics argue that such a normative position does not suit you, that it will hurt your credibility as a researcher, and that it is in any case not the researcher's job to change society. If you have dreams of this kind you should rather become a politician and suffer your disillusions there.

But there is good reason to ask who is the greatest dreamer. As I am arguing, there is in any case a value perspective at the heart of a research project.
Max Weber discussed this as the 'value-orientation'. The problem in academia is that there is a tendency for the researcher to gain something from being unconscious about his or her values as a researcher. This kind of value somnambulism only communicates in an unclear and unsystematic way, and promotes moral opportunism in the university system. It becomes fully acceptable for the researcher not to heed his or her own system of values because it is more profitable to do other kinds of research. This is a side effect of ethical neutrality that Max Weber may not have anticipated the enormity of, writing a hundred years ago.

What matters is to be an expert on how the status quo works, whether it is the thriving development of new subgenres in reality TV or the speed of development in the broadband business. The expert status of researchers rests on the usefulness of their results for commercial and political aims that by and large promote the current technological order, economic growth and trendy cultural life forms. The researcher often changes methods and theories in concert with changes in media relations, without this really being necessary. In some cases this may even be manipulatory, because the new methods may be so closely related to the new technologies that their output can almost be determined in advance.

Because of this trend-spotting mentality, the role of media researcher is often confused with the role of media commentator. When a researcher takes part in a public radio or television program or is interviewed in the newspaper, he or she must necessarily play by the rules of popular journalism. Research-based lines of argument can hardly be presented at all. This makes it reasonable to question the role that the researcher has when he or she actually takes part in the public sphere. May it be that this is mere signposting? How do you know that it is not your vanity that makes you participate in the debate?

It is a well-known fact that much research is done mainly for reasons of recognition and economic reward. It is quite valuable to have expert status, since you receive extra income from lectures and public presentations, book publications, consultancy work and the like. In addition comes the power involved in being part of state councils or boards, and the celebrity status that frequent press interviews and appearances on TV talk shows and debates give.

It may well be that media researchers should stop being participants in the media public, because they could receive better working conditions by 
staying outside it. Media research could likely also exist as a societal force completely independently of public appearances in the mass media. This is in practice the case in Great Britain, where media researchers have a very modest role in the pages of daily newspapers and on radio and TV. In Norway this situation may sound strange, because media researchers play a prominent part in the public sphere. But such a withdrawal might have produced more morally rigorous and purposeful research projects.

\section{The Instructive Position}

In closing I want to clarify my view on what perspective the researcher should have on his or her effort to understand the mass media. The crucial question is where is the researcher is located in comparison with other central actors in the field.

I will make a broad distinction between those working within and outside the media business, because this is important for the loyalties that are likely to arise. Journalists, technicians, producers, managers and other employees are, for all practical purposes, maintainers of a social and economic support system for themselves. They can lose their jobs, and therefore it is not strange that they are loyal to the current state of things in the media and defend it when it is attacked.

In stark contrast to these media professionals you have the common users, or laypeople, who have no particular attachment to the media businesses, and who are for all practical purposes socially and economically powerless in their face. There is no reason for laypersons to have any bonds of loyalty to the current state of affairs in the mass media. Indeed, they may have interests that run counter to those of the industry.

The media researcher also clearly lives outside the media systems, at least if he or she works at a university or an independent research institution. But the researcher is certainly not powerless towards them! As a researcher you have tremendous resources of knowledge at your disposal, along with highly efficient ways of learning about new or old things. Because of this command of information you have a real opportunity to change the media system, and to promote other forms of behaviour among the people within and outside the media.

I am promoting a research position that can be called instructive media research. In this approach a clear value position is (at least tentatively) formulated, the methodological resources being directed at investigating this value position's public expression in the current media mix. Based on the subsequent empirical results, one can give sound advice about how the value can be promoted within a given section of society. In Norway in particular, far more researchers should assume this active research position, since so much research is state-financed and is therefore relatively independent of commercial interests.

Lars Nyre, Ph.D., Researcher, Department of Information Science and Media Studies, University of Bergen, lars.nyre@infomedia.uib.no 